\title{
The Invisibility of Children in Data Systems
}

\author{
Michael Rigby, Shalmali Deshpande, Daniela Luzi, \\ Fabrizio Pecoraro, Oscar Tamburis, Ilaria Rocco, \\ Barbara Corso, Nadia Minicuci, Harshana Liyanage, \\ Uy Hoang, Filipa Ferreira, Simon de Lusignan, \\ Ekelechi MacPepple and Heather Gage
}

\begin{abstract}
In order to assess the state of health of Europe's children, or to appraise the systems and models of healthcare delivery, data about children are essential, with as much precision and accuracy as possible by small group characteristic. Unfortunately, the experience of the Models of Child Health Appraised (MOCHA) project and its scientists shows that this ideal is seldom met, and thus the accuracy of appraisal or planning work is compromised. In the project, we explored the data collected on children by a number of databases used in Europe and globally, to find that although the four quinquennial age bands are common, it is impossible to represent children aged $0-17$ years as a legally defined group in statistical analysis. Adolescents, in particular, are the most invisible age group despite this being a time of life when they are rapidly changing and facing increasing challenges. In terms of measurement and monitoring, there is little progress from work of nearly two decades ago that recommended an information system, and no focus on the creation of a policy and ethical framework to allow collaborative analysis of the rich anonymised databases that hold real-world people-based data. In respect of data systems and surveillance, nearly all systems in European society pay lip service to the importance of children, but do not accommodate them in a practical and statistical sense.
\end{abstract}

Keywords: Data; indicators; child health; primary care; database; children; medical record system; computerised

(C) European Commission. Published by Emerald Publishing Limited. This chapter is published under the Creative Commons Attribution (CC BY 4.0) licence. Anyone may reproduce, distribute, translate and create derivative works of this chapter (for both commercial and non-commercial purposes), subject to full attribution to the original publication and authors. The full terms of this licence may be seen at http://creativecommons.org/licences/by/4.0/legalcode 


\section{Counting and Understanding Infants, Children and Adolescents}

In order to assess the state of health of Europe's children, or to appraise the systems and models of healthcare delivery, data about children are essential, with as much precision by small group characteristic, and accuracy of data, as possible. Unfortunately, the experience of the Models of Child Health Appraised (MOCHA) project and its scientists shows that this ideal is seldom met, and thus, the accuracy of appraisal or planning work is compromised. Indeed, the opening paragraph of Chapter 1 was not able to put an exact figure on the number of children in Europe as children aged $0-17$ years inclusive are not a recognised statistical demographic grouping; similarly, it could not accurately identify the proportion of health activity performed by primary care as primary care activity is not a healthcare activity statistic despite primary care being set as the core component of health care. These challenges neatly summate the problems facing all who seek to study child health or related healthcare activity, as this involved measuring the unquantified.

Within the 30 European Union (EU) and European Economic Area (EEA) countries, the total reported population in 2017 was 514 million. Of this, there are roughly 97 million children younger than 18 years, accounting for around $19 \%$ of the total EU and EEA population (United Nations Population Division, 2017). The fact that we cannot even state definitively the total number of children in Europe starts to highlight the problem. Children form a large, important population group who have specific health needs. Non-communicable diseases present as the highest morbidities within this age group, while injuries and accidents account for the highest mortalities. These diseases and health events are largely preventable. But if we cannot count them, let alone by health or other characteristic, Europe is going to fail them.

\section{Basic Registration Data}

Population data within the European Region are collected through vital statistics registrations, national surveys and other government records. These data are available through published secondary databases, allowing the public to access information through simple online interfaces. Databases include the WHO Health for All (HFA) database, the Health Behaviours in School-aged Children (HBSC) portal, the Eurostat statistics database and the Global Burden of Disease (GBD) results tool, among others, and these are considered in more detail in following sections.

However, most current literature for child health data only focuses on mortality rates for children younger than five years of age. Meanwhile, little if any comparable data are present for children and adolescents (5-17 years of age). Further, there is sparse systematic data collection on the burden of disease (fatal and nonfatal) and injuries in this age group, even though these are some of the leading causes of child and adolescent morbidity (Global Burden of Disease, 2016). Lastly, public access means to routine vital statistics collected to ascertain mortality rates for children and adolescents are also partial or missing completely. The absence of this data has an impact on aspects of health service provision (health expenditure, workforce, etc.), which leads to suboptimal health care for children. 
In an effort to reduce morbidity and mortality, achieving universal health coverage (UHC) has been a significant goal of WHO, and progress within the WHO European Region has involved the expansion of coverage of essential interventions for children. Though there has been progress, further improvement is still needed in order to avoid deaths from preventable causes. It is evident that further refinement of existing and introduction of improved health-promoting and healthprotecting policies and interventions are required to reduce risky behaviours and to promote healthy habits (World Health Organization Regional Office for Europe, 2014; World Health Organization Regional Office for Europe, 2016).

In order to introduce the most effective policies to improve quality of care, WHO recommends implementing evidence-based guidelines for patient management. Their guidance emphasises that healthcare provision should adhere to an evidence base, and that treatments should be based on guidelines that follow international scientific evidence (World Health Organization Regional Office for Europe b, 2016). In this case, information and data are an essential resource for healthcare systems and health services. To supplement this, epidemiological data and vital statistics are central to policymaking and guidelines. Accurate information and a wide range of core indicators separated into age, gender, geographical and socio-economic status (SES) components can improve health status monitoring over time (World Health Organization Regional Office for Europe, 2017).

A specific focus on collecting child and adolescent health data is required so that policies and interventions may correctly target the health needs of this population group. Clinicians, policymakers and researchers need top class evidence to support decision-making in child health. Many databases are available and present this type of data on simple online interfaces. This includes the WHO HFA database, the HBSC portal, the Eurostat statistics database and the GBD results tool, among others. Separately, these databases provide rich data on specific aspects of child health at different ages throughout childhood and adolescence. However, none of these databases contain data on the full spectrum of child health indicators as determined by the 'Child Health Indicators of Life and Development' (CHILD) Project, which in 2002 recommended a set of indicators that cover health determinants, health status and the well-being of children with specific definitions for each indicator (Rigby \& Köhler, 2002; Rigby, Köhler, Blair \& Mechtler, 2003). It is difficult to combine data from these different sources to present a holistic picture of child health, since all databases use different methodologies. Investigations into these databases show that children are largely unaccounted for, and where there are data, they are not present for all ages.

\section{The Databases Available and Included Child Health Indicators}

\section{WHO Health for All Explorer}

Access to explorer via https://gateway.euro.who.int/en/hfa-explorer/

The WHO European HFA explorer was launched in 2016 as an easy tool to access health data and information, where the information tool allows the user to select indicators and view data from the last 36 years. This information tool is 
available on the 'European Health Information Gateway' and consists of three datasets: European HFA dataset, European Mortality Indicator dataset (MDB) and European database on human and technical resources (HRes) for health dataset. The HFA dataset includes indicators on basic demographics, health status, health determinants and risk factors. The MDB presents age-specific and gender-specific analyses of trends by broad disease groups, as well as disaggregated to 67 specific causes of death. The HRes dataset provides statistics on HRes for health and offers data on healthcare resources (World Health Organization Regional Office for Europe, 2017; World Health Organization Regional Office for Europe, 2018a). Combined, these three datasets offer information on 1,503 indicators for the 53 countries of the WHO European Region. Population-weighted averages are also available for specific groups of countries, if more than $80 \%$ of the countries in the group have data available in the given year. Some data can also be sorted by gender.

Although the WHO HFA explorer is an extremely rich information source, there are some noticeable problems particularly for the child population. Firstly, the database does not allow the user to sort indicator data by small age groups (e.g. 1-4 years, 5-9 years, 10-14, and so on). In considering child health, this is a fundamental flaw since the available data cannot accurately represent the numbers or health status of children, since the accepted international definition is of those between birth and their 18th birthday. Put simply and starkly - the HFA explorer cannot explore the numbers or health of children in Europe as it cannot compute them as a statistical group. For example, child mortality data are presented as either crude rates for 0 - and 1-4-year-olds or age-standardised rates for $0-14-, 1-19$ - or 5-14-year-olds. Moreover, these data are only present for certain causes of death. Secondly, there are not enough child health indicators included in the database to provide comprehensive information on the health of children in the European Region to make informed policy decisions. The user can access some population data, mortality data, immunisation coverage and one socio-economic indicator (Table 7.1).

Lastly, although these health indicators are present in the data explorer, much of the data are missing or are not recent. Further indicators are available through the 'European Health Information Gateway' website under the Child and Adolescent Health dataset World Health Organization Regional Office for Europe, 2018b). The database includes the indicators mentioned in Table 7.1 and also includes the following:

- child immigrant population of 0-14-year-olds;

- child population at risk of poverty or social exclusion of 0-15-year-olds;

- minimum age of criminal responsibility;

- potential criminal liability for children;

- HPV vaccine coverage; and

- tuberculosis cases in children. 
Table 7.1. Overview of child health indicators available on the WHO Health for All explorer.

\begin{tabular}{|c|c|}
\hline Child Health Indicator & Source \\
\hline Life expectancy at age 1 & HFA \\
\hline Life expectancy at age 15 & HFA \\
\hline Population aged $0-14$ years & HFA \\
\hline Probability of dying before age 5 & HFA \\
\hline Proportion of children of official primary school age not enrolled & HFA \\
\hline Neonatal and perinatal mortality & HFA \\
\hline $\begin{array}{l}\text { Proportion of infants vaccinated against invasive disease due to } \\
\text { Haemophilus influenzae type } b\end{array}$ & HFA \\
\hline Proportion of children vaccinated against measles & HFA \\
\hline Proportion of children vaccinated against diphtheria & HFA \\
\hline Proportion of children vaccinated against hepatitis B & HFA \\
\hline Proportion of children vaccinated against mumps & HFA \\
\hline Proportion of children vaccinated against pertussis & HFA \\
\hline Proportion of children vaccinated against poliomyelitis & HFA \\
\hline Proportion of children vaccinated against rubella & HFA \\
\hline Proportion of children vaccinated against tetanus & HFA \\
\hline Proportion of children vaccinated against tuberculosis & HFA \\
\hline Certain cause specific crude mortality data for 0 -year-olds & MDB \\
\hline Certain cause specific crude mortality data for 1 -4-year-olds & MDB \\
\hline Certain cause specific standardised mortality data for 0 -14-year-olds & MDB \\
\hline Certain cause specific standardised mortality data for 1-19-year-olds & MDB \\
\hline Certain cause specific standardised mortality data for 5-14-year-olds & MDB \\
\hline
\end{tabular}

Similarly, for these indicators, the user cannot disaggregate data in small age groups. Lastly, there are incomplete data for these indicators, too. For example, the HPV vaccine coverage data only contain 18 values from 18 different countries, over six years. Most of the countries report only one value, but for different years.

The issues with this database are important since they directly affect a major database used by policymakers, health professionals and researchers. The sparse and incomplete child health dataset does not provide substantial information, in order to make a well-informed, evidence-based health policy. 


\section{Health Behaviour in School-aged Children (HBSC) Data Portal}

Access to portal via http://hbsc-nesstar.nsd.no/webview/

A second database for child health is the WHO/Europe collaboration with the HBSC survey, which collects information on health, well-being, social environment and health behaviour. This survey is conducted in 41 European countries and regions using a standardised questionnaire, allowing for the collection of common data from all participating countries for cross-national comparisons (World Health Organization Regional Office for Europe, 2018c). The survey collects information on 11-, 13-, and 15-year-old children since these ages have been reported as a time of increasing autonomy, which influences the development of their health and health-related behaviours (Health Behaviour in Schoolaged Children, 2018).

Findings from the survey are published every four years, and the data are presented in an online data portal. Presently, data on the portal are available from 2001/2002, 2005/2006, 2009/2010 and 2013/2014, allowing analysis of trend data (HBSC Data portal, 2018). This data are also available through the Child and Adolescent Health dataset on the 'European Health Information Gateway'. The HBSC portal allows disaggregation of data into gender, school grade, birth month or year, age or age category, country of birth and parental country of birth. The portal allows the user to compile data into a table, adding as many child health indicators as desired. The child health indicators are separated into health behaviours, health outcomes, risk behaviours, social context and social inequity (Figure 7.1).

This dataset is unique, in that it focuses on behaviours established during childhood that may continue into adulthood and have an impact on health outcomes. Additionally, the study focuses on young people in their social context at home, at school and with their family and friends. The combination of these factors, individually and together, is studied as influencers of young people's health from childhood into young adulthood (HBSC Data portal, 2018). The findings from the study help to monitor young people's health, understand the determinants of health and to improve health interventions.

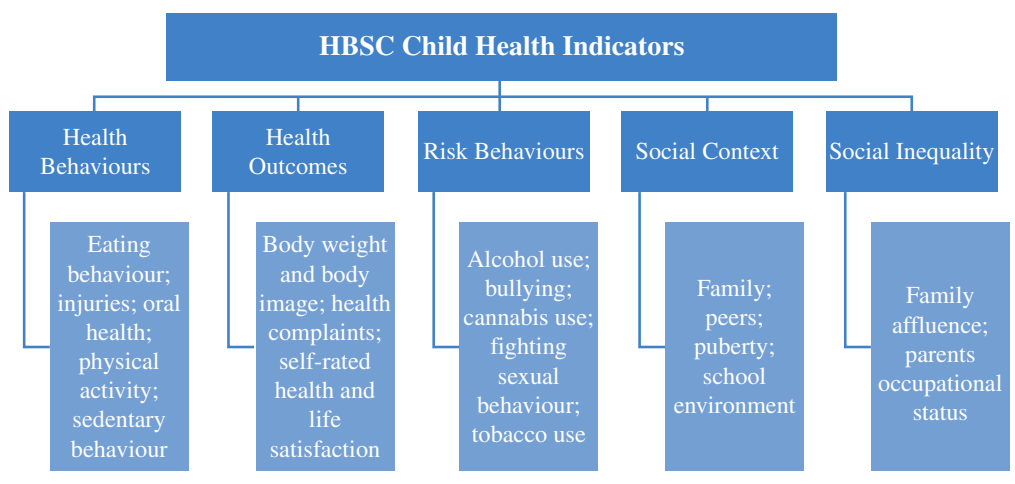

Figure 7.1. Overview of child health indicators available through the HBSC portal. 
Although this dataset is widely praised and used by the WHO European Region, there are some limitations that should be pointed out. Firstly, although the remit of HBSC is to investigate HBSC only, the lack of investigations of these health behaviours in younger children and for all ages (e.g. 10-, 12- and 14-year-olds) presents a gap in the evidence base. Although it is possible to assume that health behaviours might be similar to 11-, 13- and 15-year-olds, this assumption is not robust for evidence-based policymaking. Secondly, the survey methods are designed such that the study takes place every four years, and so data are not collected for the years in between. It is difficult to generate comprehensive trend data in order to monitor policy development and child health research.

A third point concerning this dataset is over the sampling techniques used to identify the specific schools to partake in the survey. Overall, cluster sampling is used to choose school class or schools, in the absence of a sampling frame of classes. Cluster sampling tends to provide less precision than other sampling methods, such as simple random sampling or stratified sampling (Roberts et al., 2009)

Fourthly, the questionnaire is also subject to some criticism, namely, selfreported answers and changes in questions over time. Though subtle, there are some questions and choices for questions that have changed from survey to survey, for example, the variation in questions asked around tobacco use. Further, since the collected responses are self-reported, the reliability of data can be questioned, since certain questions may provoke emotions leading to the young person answering differently to the truth.

Lastly, the emphasis on lifestyle, social and behavioural child health indicators means data on child health systems and policy data, and child health status and well-being data, are missing. Thus, this database too does not provide data on a full range of child health indicators for evidence-based policy action.

\section{Eurostat}

Access to database via https://ec.europa.eu/eurostat/data/database

A third database is provided by Eurostat, the statistical office of the EU which provides high-quality, comparable statistics at European level. Data are collected, verified and analysed by Member States and consolidated by Eurostat using a harmonised methodology to ensure data are comparable. The Member States and Eurostat work together to define a common methodology when collecting national data. Data are collected for nine different themes: general and regional statistics; economy and finance; population and social conditions; industry, trade and services; agriculture and fisheries; international trade; transport; environment and energy; and science, technology and digital society (Eurostat, 2018a). Health data are present within the theme 'population and social conditions'.

Eurostat presents European health statistics on both objective and subjective parts of population health. The data are presented in a data navigation tree, which allows the user to choose variables and create tables on the portal. Data for public health (health status, health determinants, health care, morbidity, 


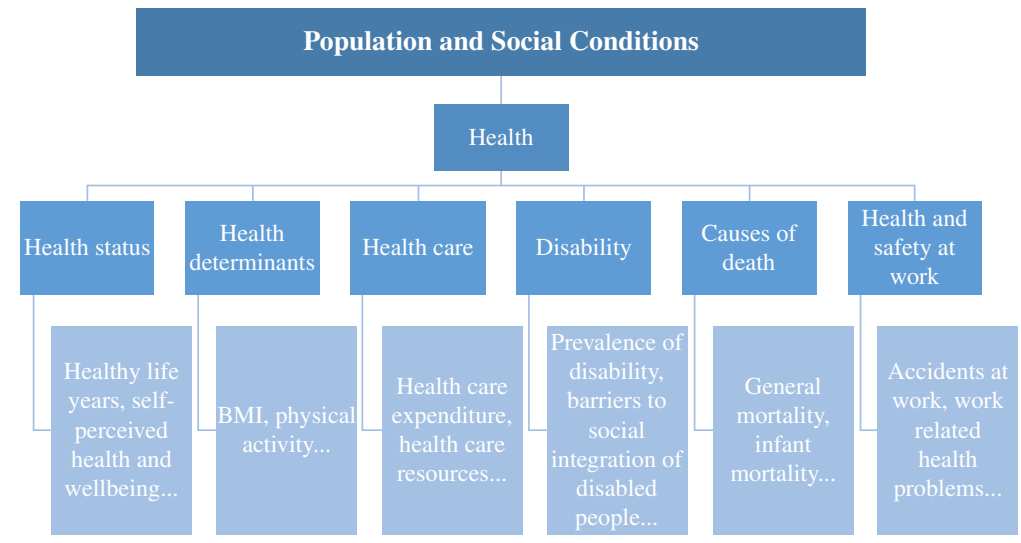

Figure 7.2. Overview of health indicators available through the Eurostat database.

disability and causes of death) and for health and safety at work (accidents at work and occupational diseases) are available in Eurostat (Figure 7.2).

Data are regularly updated with a few health indicators having undergone a recent update to include data from 2017. Health status and health determinant indicators consist mainly of self-reported data, which are associated with response bias. Depending on the indicator chosen, the data can be disaggregated into age, gender, country, labour status, degree of urbanisation, educational attainment and others. This information is useful since it allows comparisons between specific groups within countries, as well as among countries. However, it should be noted that this level of disaggregation is only available for certain indicators and is not available for child health at all.

When it comes to child health indicators, this database seems to disregard this population group completely. Unfortunately, though data for these health indicators can be sorted by age group, the youngest available age group is 15-19-year-olds, suggesting that data on childhood and early adolescence are not collected. Youth are allocated a specific section under 'population and social conditions' and within this category, youth health is present. There are nine indicators present under youth health that incorporate some information on health status, health determinants and causes of death (Table 7.2).

This 'folder' dedicated to youth health suggests that this topic and this population group have been considered and studied. However, the indicators available in youth health, yet again, do not account for any person under the age of 15 , representing a lack of child morbidity data. In spite of this, there is one health indicator that does present data for children younger than 15 years: causes of death. Data on causes of death provide information on mortality patterns and data are presented in five-year age groups, which allows meaningful comparisons between countries and regions (Eurostat, 2018b), but not for the totality of childhood. There are 86 listed causes of death available through 
Table 7.2. Overview of child health indicators on the Eurostat database.

\begin{tabular}{ll}
\hline Child Health Indicator & Variables Available to Sort By \\
\hline Daily smokers of cigarettes & $\begin{array}{l}\text { Gender, age, educational } \\
\text { attainment level, income quintile }\end{array}$ \\
\hline Body mass index & $\begin{array}{l}\text { Gender, age, educational } \\
\text { attainment level, income quintile }\end{array}$ \\
Crude death rate by suicide of young people & Gender, age \\
Psychological distress of young people & Gender, age \\
$\begin{array}{l}\text { Persons reporting an accident resulting in } \\
\text { injury }\end{array}$ & $\begin{array}{l}\text { Gender, age, educational } \\
\text { attainment }\end{array}$ \\
$\begin{array}{l}\text { Self-reported unmet needs for medical } \\
\text { examination }\end{array}$ & $\begin{array}{l}\text { Gender, age, main reason } \\
\text { declared, income quintile }\end{array}$ \\
$\begin{array}{l}\text { Self-perceived health } \\
\text { People having along-standing illness or } \\
\text { health problem }\end{array}$ & Gender, age, income quintile \\
$\begin{array}{l}\text { Self-perceivedlong-standinglimitationsin } \\
\text { usualactivitiesduetohealthproblem }\end{array}$ & Gender, age, income quintile \\
\hline
\end{tabular}

Eurostat, sorted by ICD10, and mortality data are available as absolute numbers, crude death rates and age-standardised rates. Therefore, comprehensive mortality data are available for children and adolescents. This includes data on injuries and NCDs, two of the most common causes of mortality and morbidity in children and adolescents, respectively.

\section{Global Burden of Disease (GBD) Results Tool}

Access to results tool via http://ghdx.healthdata.org/gbd-results-tool

A further database is the GBD results tool developed by the Global Health Data Exchange (GHDx) as a part of the Institute for Health Metrics and Evaluation (IHME), which launched in July 2007. The IHME is a population health research centre based at the University of Washington that provides morbidity and mortality data on the health status of the global population and is funded by the Bill \& Melinda Gates Foundation (Institute for Health Metrics and Evaluation, 2018a).

The GHDx comprises information from surveys, censuses, vital statistics and other health-related databases, which is available for analysis and comparison through the results tool. GHDx aims to provide the best information on population health in order to improve health outcomes. This portal allows the user to build tables of information while selecting from nine different variables. The database contains data for 335 causes of morbidity and mortality, 84 risk factors, 19 aetiological factors and 39 impairment factors. In addition to this, the database can also present data on disability-adjusted life years (DALYs), years 

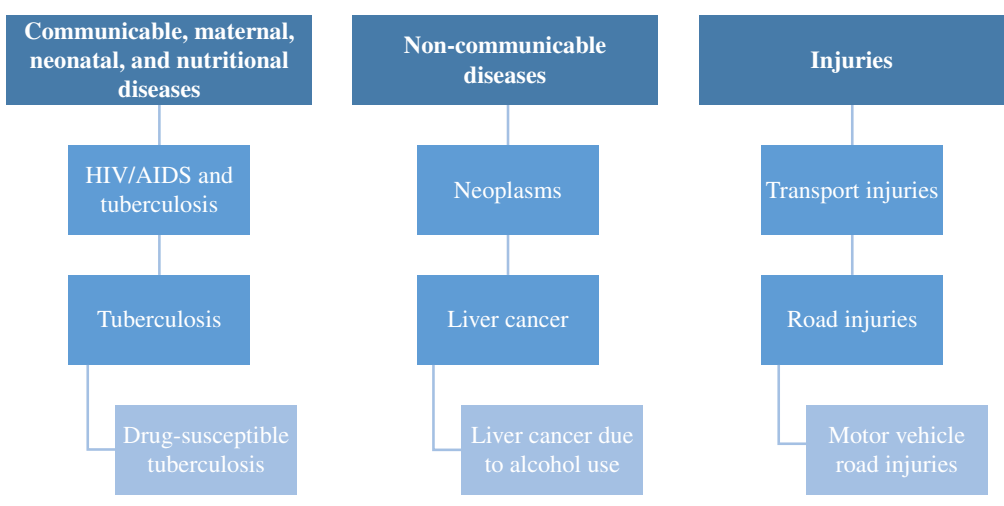

Figure 7.3. Example of the four levels of hierarchy for causes of mortality.

lived with disability (YLDs), years of life lost (YLLs), prevalence, incidence, life expectancy and maternal mortality ratios, among others (Institute for Health Metrics and Evaluation, 2018b). In other words, the database can paint a very clear picture of the burden of disease across the world.

The data are categorised using a self-specified 'cause hierarchy' separating causes of mortality into four levels (Figure 7.3). Top level categories include the following:

- communicable, maternal, neonatal and nutritional diseases;

- non-communicable diseases; and

- injuries.

It is apparent that there is a large range of data that can be sorted to reveal a very fine level of detail. This type of data is not only useful for establishing burden of disease and rates of mortality, but also for monitoring health policies and interventions and evaluating their impact.

From child health perspective, data are available for children of all age groups, from 195 countries and territories, and are available from 1990 to 2016. Child data can be disaggregated in 11 age groups:

(1) early neonatal;

(2) late neonatal;

(3) post-neonatal;

(4) under 1 year;

(5) $1-4$ years;

(6) under 5 ;

(7) $5-9$ years;

(8) 5-14 years;

(9) 10-14 years;

(10) 15-19 years; and

(11) under 20 years. 
This database provides the most complete picture of child morbidity and mortality of all the databases available for public use. Data on the most common causes of child and adolescent mortality and morbidity (injuries, NCDs, mental health and substance abuse) are also available from this database. This information is very useful for tracking the health status of European children; however, still absent is data for SES, behavioural or country policy stances. This makes it difficult to attribute reasons for trends in mortality rates and to draw a comprehensive overview of children's health.

An addition enigma with the GBD tables is that there is a strong drive for completeness of data to enable comprehensive comparative analyses; therefore, the process computes missing value to create a putative complete dataset. However, some of this computation can be opaque, though the team are open about the principle (Leach-Kemon \& Gall, 2018). Users may, however, be concerned that they may not know which data are real facts and which are assumptions

\section{World Bank Open Data and DataBank}

Access to portal via https://data.worldbank.org/

The World Bank understands the need for good data in order to 'set baselines, identify effective public and private actions, set goals and targets, monitor progress, and evaluate impacts' (World Bank, 2018a). Resultantly, it provides a database that focuses on delivering good-quality statistical data for Member countries. There are 189 Members countries in the World Bank, who govern the World Bank Group. Data are obtained from the statistical system of a country, and therefore, the quality is dependent on the performance of a country's national systems. In order to maintain a high quality, the Development Data Group, within World Bank, coordinates with other organisations to improve the capacity of Member countries to produce and use statistical information. In addition, professional standards are followed for the collection, compilation and dissemination of data to ensure data quality and integrity.

World Bank Open Data allows the public free and open access to global developmental data (World Bank, 2018b). These data can be browsed by countries and economies or by indicators. When searching by country, the database presents data for individual countries, as well as groupings such as region, income levels, small states and so on. When looking through indicators, data are categorised into 21 indicators, of which 'health' is one (Figure 7.4).

Investigation into the health section reveals 52 indicators including data on population rates, vital statistics, mortality rates, life expectancy, incidence and prevalence of infectious diseases and so on (see Table 7.3). The information is presented in a clear online format and can also be downloaded via an online visualisation tool or as a spreadsheet.

Although a wide range of indicators are available, this database provides data for the set indicator only and does not allow the user to sort data, for example by age groups. Furthermore, of the 52 indicators available, just over a quarter mention some form of child health or involve data for children within 

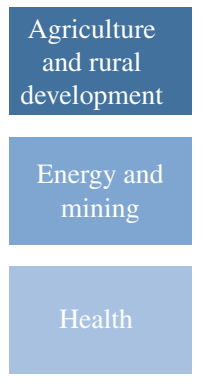

Public sector
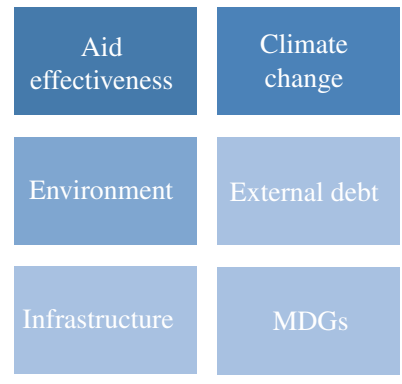

Science and technology
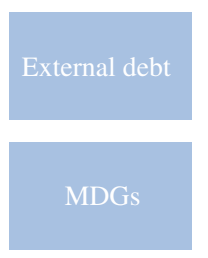

Social

development
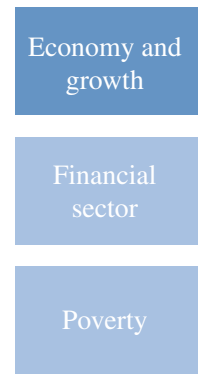

Social

protection and

labour

\section{Education}
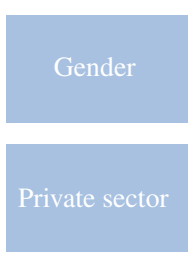

Trade

\section{Urban}

development

Figure 7.4. Overview of indicators available through World Bank Open Data database.

the $0-18$ years age range, but even then not specifically for that legal childhood definition.

These data are also available through the World Bank DataBank, an analysis and visualisation tool that holds time series data and comprises 71 databases (2018c). Upon searching for 'health', seven databases are presented: Gender Statistics, Health Nutrition and Population Statistics, Population estimates and projections, Service Delivery Indicators, UHC and Human Capital Index. A few further indicators are available through these databases, where, for example through the 'Health, Nutrition and Population Statistics' database, information is available on children and HIV, diarrhoea treatment, population stratified by quintile age groups and gender, school enrolment and vitamin A supplementation coverage rate. However, it still does not allow disaggregation of data into small age groups.

\section{Central Intelligence Agency - The World Factbook}

Access to Factbook via https://www.cia.gov/library/publications/the-worldfactbook/

The Central Intelligence Agency (CIA) of the US government presents a World Factbook that is a resource containing summary information on demographic, geographic, governmental, economic and military data on each of the 267 world entities (Central Intelligence Agency, 2018) - in this context, entities comprise independent countries, Taiwan, the EU, dependencies and areas of special sovereignty, Antarctica and places in dispute and the world and the oceans. Although this information is primarily designed for the use of US government officials, it is open to the public as a research resource. Information is available for each country on a profile and includes a map of the country, the flag, as well 
Table 7.3. List of health indicators available through World Bank Open Data database.

Adolescent fertility rate (birthsper1,000women ages 15-19)

Age dependency ratio (\% of working-age population)

Birth rate, crude (per 1,000 people)

Births attended by skilled health staff ( $\%$ of total)

Causeofdeath, by communicable diseasesandmaternal,prenatalandnutrition conditions(\%oftotal)

Cause of death, by injury (\% of total)

Cause of death by non-communicable diseases (\% of total)

Completeness of birth registration (\%)

Completeness of death registration with cause-of-death information (\%)

Contraceptive prevalence, any methods (\% of women ages 15-49)

Death rate, crude (per 1,000 people)

Diabetes prevalence (\% of population ages 20-79)

Fertility rate, total (births per woman)

Hospital beds (per 1,000 people)

Immunisation, DPT (\% of children ages 12-23 months)

Immunisation, measles ( $\%$ of children ages 12-23 months)

Incidence of tuberculosis (per 100,000 people)

International migrant stock, total

Life expectancy at birth, female (years)

Life expectancy at birth, male (years)

Life expectancy at birth, total (years)

Maternal mortality ratio (modelled estimate, per 100,000 live births)

Mortality caused by road traffic injury (per 100,000 people)

Mortality rate, infant (per 1,000 live births)

Mortality rate, neonatal (per 1,000 live births)

Mortality rate, under 5 (per 1,000 live births)

Net migration

Number of surgical procedures (per 100,000 population)

Population ages $0-14$ (\% of total)

Population ages 15-64 (\% of total)

Population ages 65 and above (\% of total)

Population growth (annual \%)

Population, female ( $\%$ of total) 
Table 7.3. (Continued)

Population, total

Pregnant women receiving prenatal care (\%)

Prevalence of HIV, female (\% ages 15-24)

Prevalence of HIV, male (\% ages 15-24)

Prevalence of HIV, total (\% of population ages 15-49)

Prevalence of anaemia among children (\% of children under 5 )

Prevalence of overweight, weight for height (\% of children under 5)

Prevalence of severe wasting, weight for height (\% of children under 5)

Prevalence of stunting, height for age (\% of children under 5 )

Prevalence of undernourishment (\% of population)

Prevalence of underweight, weight for age (\% of children under 5)

Prevalence of wasting, weight for height ( $\%$ of children under 5 )

Refugee population by country or territory of asylum

Refugee population by country or territory of origin

Risk of catastrophic expenditure for surgical care ( $\%$ of people at risk)

Risk of impoverishing expenditure for surgical care (\% of people at risk)

Specialist surgical workforce (per 100,000 population)

Teen age mothers (\% of women ages $15-19$ who have had children or are currently pregnant)

Unmet need for contraception (\% of married women ages 15-49)

as an introduction to the country's history. Additional information is available on the geography, the people and society, the government, the economy, energy, communications, transportation, military and security, terrorism and transnational issues.

The most relevant section for the MOCHA project is 'people and society'. Within this, information on 31 indicators is available, of which thirteen indicators are directly related to health. This includes data on birth and death rates, maternal and infant mortality ratios, life expectancy data, health expenditure, physician and hospital bed density, HIV/AIDS and obesity prevalence rates. Aside from infant mortality ratio and school life expectancy, there are no other child-related indicators available.

\section{Organisation for Economic Cooperation and Development - OECD.Stat Web Browser}

Access to web browser via https://stats.oecd.org/index.aspx?DataSetCode= HEALTH_STAT 
The Organisation for Economic Cooperation and Development (OECD) focuses on policies that improve economic and social well-being of people, among its member states globally - these are mainly larger economies. These policies are based on facts and real-life experiences such as economic drivers, social and environmental change, taxation and social security, leisure time and so on (OECD, 2018a).

The OECD collects data on member countries and for some outside the OECD membership, especially though an understanding with the European Commission, and analyses this data for discussions and policy decisions. Data are available for 26 topic areas, of which one is health. This section has data on health outcomes and health system resources, as well as healthcare policies, in an effort to improve health systems within the OECD area. Within the health section, there are 13 areas that OECD focuses on, including ageing and longterm care, mental health and public health (OECD, 2018b). Notably, there is no section available on child health.

This data are available through reports, but also through OECD.Stat, a database explorer where users can search the statistical databases and easily build tables with different variables and extract data to be downloaded into MS Excel. Information on methodology and data sources is also available through this interface (OECD, 2013).

Within health, there are 12 themes: health expenditure and financing, health status, non-medical determinants of health, healthcare resources, health workforce migration, healthcare utilisation, healthcare quality indicators, pharmaceutical market, long-term care resources and utilisation, social protection, demographic references and economic references (OECD, 2018c).

Although these themes are comprehensive and inclusive of several aspects of health, there is no specific focus on child health. The child-related indicators available are infant health, maternal and infant mortality and immunisation, which do not focus on children above five years of age and do not cover the breadth of topics that are important in child health.

\section{Discussion of Key Points on Data Sources}

The information available from seven key databases shows that data for child health and policies surrounding their well-being are not widely available. The databases show little congruency between the level of information available for child health indicators and only one database allows disaggregation of data into small age groups for morbidity and mortality. The disparity in statistics and the availability of child health indicators is evident in all databases.

However, of the seven databases, Eurostat and GBD show the most accordance for child health indicators, such as mortality rates for small age groups. The GBD database can provide data on 335 causes of morbidity and mortality and gives the most comprehensive coverage for data on child health morbidity and mortality indicators. Nonetheless, data related to and around obesity for children and adolescents are missing, even though this is one of the leading causes of morbidity in this population group. Only some obesity data are 
available through HBSC though it is self-reported and therefore open to issues surrounding response bias.

These current positions of these databases show that although there is some data available for children in data and policy systems, they are largely missing. Efforts to improve health status and health outcomes within this population group will require a wider range of child health indicators and a systematic and robust database that allows manipulation of data. Not least, as Chapter 5 shows, measurement of the important and recognised significant field of Equity is greatly hampered by lack of relevant child-specific data - it is very difficult to act effectively on a societal priority if there are not the data to show what action and where is needed.

\section{Invisibility of Children in Quality Measures}

Since the early 1990s, attention has been drawn to the invisibility of children as individual entities (Chapple \& Richardson, 2009; Rees, Bradshaw, Goswami, \& Keung, 2006), often subsumed within statistics about parents, families and households. This issue has been often highlighted by other authoritative organisations, such as the OECD (2009), UNICEF (2009) and WHO (2010), which raise the question of scarcity of available data, poor data quality and the need for data harmonisation. Although efforts in this direction are increasing (Wolfe, 2014), children's statistical invisibility still limits the breadth of the analysis and therefore the evaluation of childcare, especially in the view of cross-country comparison.

The main goal of focussed work the team from CNR Italy undertook within the MOCHA project was to identify potential measures through the exploration of a continuum of feasible measures. The team sought clinical, health status and satisfaction perspectives that could be used effectively by the stakeholders within diverse structural models (across countries) and paediatric settings to quantify the impact of the paediatric care (Minicuci et al., 2017). To achieve this challenging goal, measures available in international open-accessible databases on child health-related issues as well as those used by the MOCHA countries in their evaluation of childcare were analysed. This analysis contributes to the identification of potential feasible and already available measures and at the same time helps in identifying gaps that hinder a multidimensional approach of the evaluation of primary care systems for children.

\section{The MOCHA Analysis}

All international databases that were open access and dealt with a broad spectrum of child health-related issues were searched. Scrutinised sources came from organisations, agencies, research networks and observatories. Ongoing and complete research projects on child health care were also investigated.

In parallel, an ad hoc designed questionnaire was developed and administered to Country Agents (CAs) to gather information on: 
- agencies/organisations in charge of the evaluation of quality of care at national and/or local level and/or devoting a specific part of quality assessment to childcare; and

- measures used to evaluate childcare.

Among the 30 MOCHA countries, 27 CAs responded to the questionnaire. Two CAs (Poland and Romania) reported that their assessment of healthcare system is based on accreditation procedures, while two other CAs (Greece and Malta) did not provide any measures devoted to child health care. Therefore, our analysis considered 23 countries that reported a system in place to assess the quality of child health care and also provided the measures adopted.

The development of a conceptual map of domains, further detailed in a twolevel hierarchy of subcategories, helped the classification and the comparative analysis of the data collected.

Additionally, to analyse whether the child's psychophysical development is considered within the available measures, the results were also analysed considering the coverage of child age range, to capture the level of child invisibility in both sources of information. To balance the need of granularity with the choice of standardised age ranges and with the intent of capturing the most common ones (but also the less frequent), the following age ranges have been adopted: $0-11$ months and $1-4,5-9,10-17$ and $>17$ years.

Moreover, an analysis of measures related to diseases was carried out to investigate whether and to what extent they adequately capture child-centric health issues and well-being.

In the following, two main aspects of child invisibility are analysed focusing on age and disease-related measures available in international databases as well as those used by the MOCHA countries, as reported by the CAs.

\section{Analysis of Age-related Measures}

\section{International Databases}

Among the 207 measures identified in the international databases, 157 (76\%) are age-related, and among them, 86 measures fall within the identified age groups, while the rest cover more than one age class (Table 7.4).

Two age groups are most frequently covered:

(1) the child aged less than one year (40 measures); and

(2) the child aged $10-17$ years (42 measures).

The first age group (children aged younger than one year) focuses, in particular, on the different types of vaccine administration (14 measures), on neonatal and infant mortality (eight measures) and, to minor extent, on breastfeeding (three measures) and preterm and low birth weight (three measures). Measures considering adolescents (10-17 years) are frequently related to school performance taking advantages of yearly international surveys (nine measures related to 
Table 7.4. Distribution of measures by age ranges in international databases.

\begin{tabular}{|c|c|c|c|c|}
\hline$<1$ & {$[1-4]$} & {$[5-9]$} & {$[10-17]$} & $>17$ \\
\hline $40(25 \%)$ & $3(2 \%)$ & $1(1 \%)$ & $42(27 \%)$ & 0 \\
\hline \multicolumn{5}{|c|}{$18(11 \%)$} \\
\hline \multicolumn{4}{|c|}{$12(8 \%)$} & \\
\hline \multicolumn{5}{|c|}{$19(12 \%)$} \\
\hline & & & \multicolumn{2}{|l|}{$14(9 \%)$} \\
\hline & & \multicolumn{3}{|c|}{$7(4 \%)$} \\
\hline & \multicolumn{2}{|c|}{$1(1 \%)$} & & \\
\hline
\end{tabular}

PISA (Program for International Student Assessment), three to PIRLS (Progress in International Reading Literacy Study) and two to TIMSS (Trends in International Mathematics and Science Study)), and also consider health-related behaviour such as addiction related to tobacco smoking and alcohol consumption and nutrition, concerning fruit and vegetable consumption and weight problems. The $1-4$ and 5-9 age groups are covered by a limited number of measures exclusively pertaining to family expenditures on education, leaving out other aspects that could measure this important child developmental life course.

Measures considering more than one age range are generally designed to capture disease distribution, hospitalisation, health and school health service' expenditures. They are generally related to diseases classified by ICD.

\section{Responses by the MOCHA Country Agents}

Among the 352 measures reported by the CAs, 122 (35\%) are age-related. The most frequently considered single age range is the neonatal period (29 measures), while the majority of measures $(88,72 \%)$ tend to combine more than one interval, shown in Table 7.5.

This is evident by the high number of measures $(N=51 ; 42 \%)$ that cover the $0-17$ year period of life and seven measures $(6 \%)$ that cover the whole spectrum of age ranges.

Focusing on 29 measures related to the neonatal period, particular emphasis is posed on birth and delivery (nine measures) and mortality (eight measures) and to a minor extent on breastfeeding (two measures) and health issues such as low weight newborns (one measure) and malfunctions (one measure). It is worth noting that within these measures, despite only being sparsely adopted by the 
Table 7.5. Distribution of measures by age ranges according to Country Agent responses.

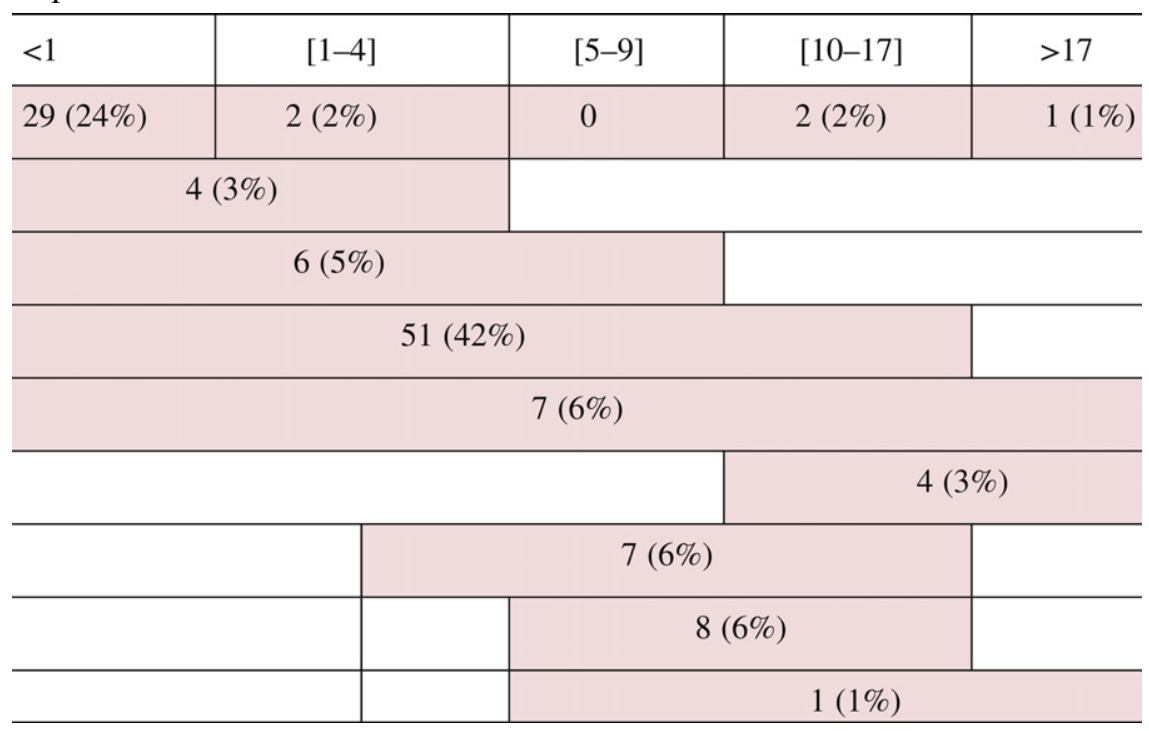

MOCHA countries, there are some attempts to evaluate the preventive functions of paediatric primary care measuring the number of neonatal children being screened during well-child visits (one measure adopted by Ireland and the other by Austria, Finland, Greece, Ireland and Portugal).

Focusing on the consistent number of measures covering the entire range of age groups, the majority of them ( 37 measures out of 58) consider childhood and adolescence as a whole period, without making any age group distinction. These measures are generally related to hospitalisation rates due to pathologies or track the prevalence/proportion of certain diseases. Moreover, the large majority of these measures are heterogeneously and sparsely distributed among the 23 countries, with the highest peak of eight countries using the same type of measure.

\section{Analysis of Disease-related Measures}

\section{International Databases}

Fifty-eight out of 207 measures (23\%) are disease-related, covering 30 different pathologies, as shown in Figure 7.5. Eleven measures provide a wide spectrum of diseases using the ICD classification focusing mainly on hospitalisation (discharge and length of stay, four measures) and mortality (two measures). The three measures related to health expenditures distributed by ICD provide data about a limited number of countries: a maximum of five EU/EEA countries provide data to international databases. 


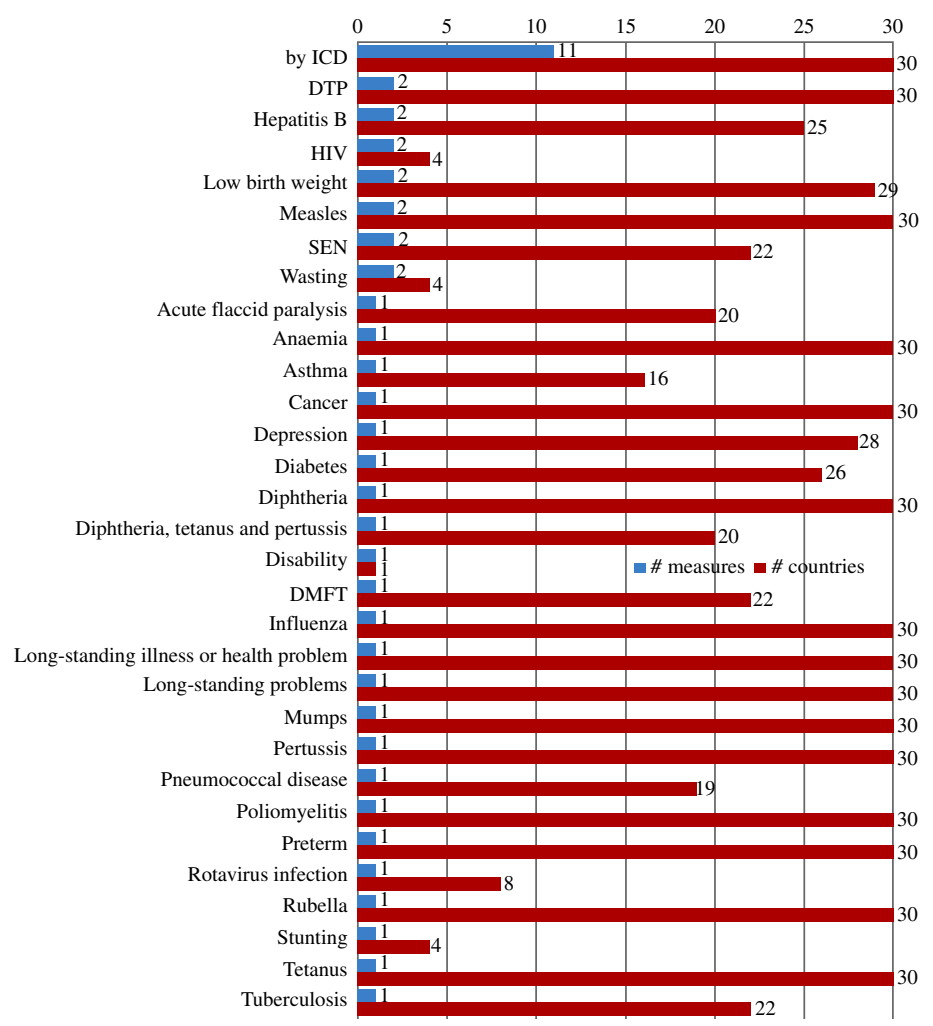

Figure 7.5. Distribution $(n)$ of measures available in international databases by disease - total number of countries providing data for at Least One measure related to the specific disease.

Similar to the age-related measures, the remaining measures are mainly focused on immunisations (17 measures) and morbidity (10 measures). However, data on morbidity only unevenly cover all the EU/EEA countries, especially when they are related to specific diseases such as HIV or severe wasting (four countries covered). Also in diseases common in childhood, such as asthma, national data available in international databases partially cover the MOCHA countries (16 countries report the prevalence of asthma in children ages $6-7$ or 13-14).

\section{Responses by Country Agents}

About 173 out of $352(49 \%)$ measures reported by CAs are related to diseases covering 50 different pathologies. Data gathered by CAs allowed us to analyse them under different perspectives. First, to explore whether a set of measures are commonly used across countries to evaluate child health care related to diseases. This analysis provided indications on the frequency of use across 
countries (i.e. the number of countries using the same or similar measures). It also highlighted whether there is a convergence in the evaluation on certain aspects of child health care (types of diseases analysed). Second, we investigated the number of measures that are used to evaluate a specific aspect of child health care. This indicates the efforts of an in-depth evaluation through the selection of different measures that capture detailed aspects that contribute to a more comprehensive analysis. In the case of diseases, this may also indicate countries' concerns on specific child disorders, whose prevalence needs particular monitoring efforts.

Figure 7.6 shows that countries' assessment on children diseases tends to use a higher number of measures concentrated on a limited number of diseases, while a consistent number of diseases are analysed by one measure generally within a single country.

Asthma is the most frequently analysed illness in terms of both the number of measures reported by the CAs $(N=22 ; 13 \%)$ and the number of countries that focus part of the quality assessment on the basis of such measures $(N=14$, $61.0 \%)$. Similar results are provided for diabetes (16 measures and nine countries, respectively, $9 \%$ and 39\%) and for mental health (16 measures and 13 countries, respectively, $9 \%$ and $57 \%$ ). However, if we consider commonalties across countries for the analysis of these diseases, there is a peak of six countries using hospitalisation rates due to asthma and five countries adopting the incidence rate of Diabetes Type 1 and Type 2 .

Considering the overall distribution by country, there is a remarkable variation. A limited number of countries use the same or similar measures. The highest convergence is once again on immunisation rates for MMR (nine countries), DPT3 (eight countries) and meningitis (eight countries). The remaining measures are unevenly distributed between the countries, in some cases indicating particular attention on the analysis of specific diseases. For instance, Denmark uses 11 measures to report laboratory test values on diabetic children, and 12 to analyse the different aspects of asthma treatment ranging from primary care visits to hospitalisations and drug consumption. It is also the only country that monitors ADHD with eight different measures that comprise various types of visits performed and use of drugs.

\section{Quality Measures Key Points}

The analysis of measures related to age and disease available in international databases and resulting from CAs' responses provide a first snapshot of children's invisibility. If we consider the age-related measures, the major focus is on maternal and prenatal health and on the first years of childhood. This is especially the situation at country level, where the attention on age groups is not so diffused (35\% of measures applying this distinction). Conversely, international databases tend to consider also adolescents mainly under the perspective of healthy behaviour and school performance. Infant age and early childhood (1-4 years and 5-9 years) are the most invisible ones, even if often included in 


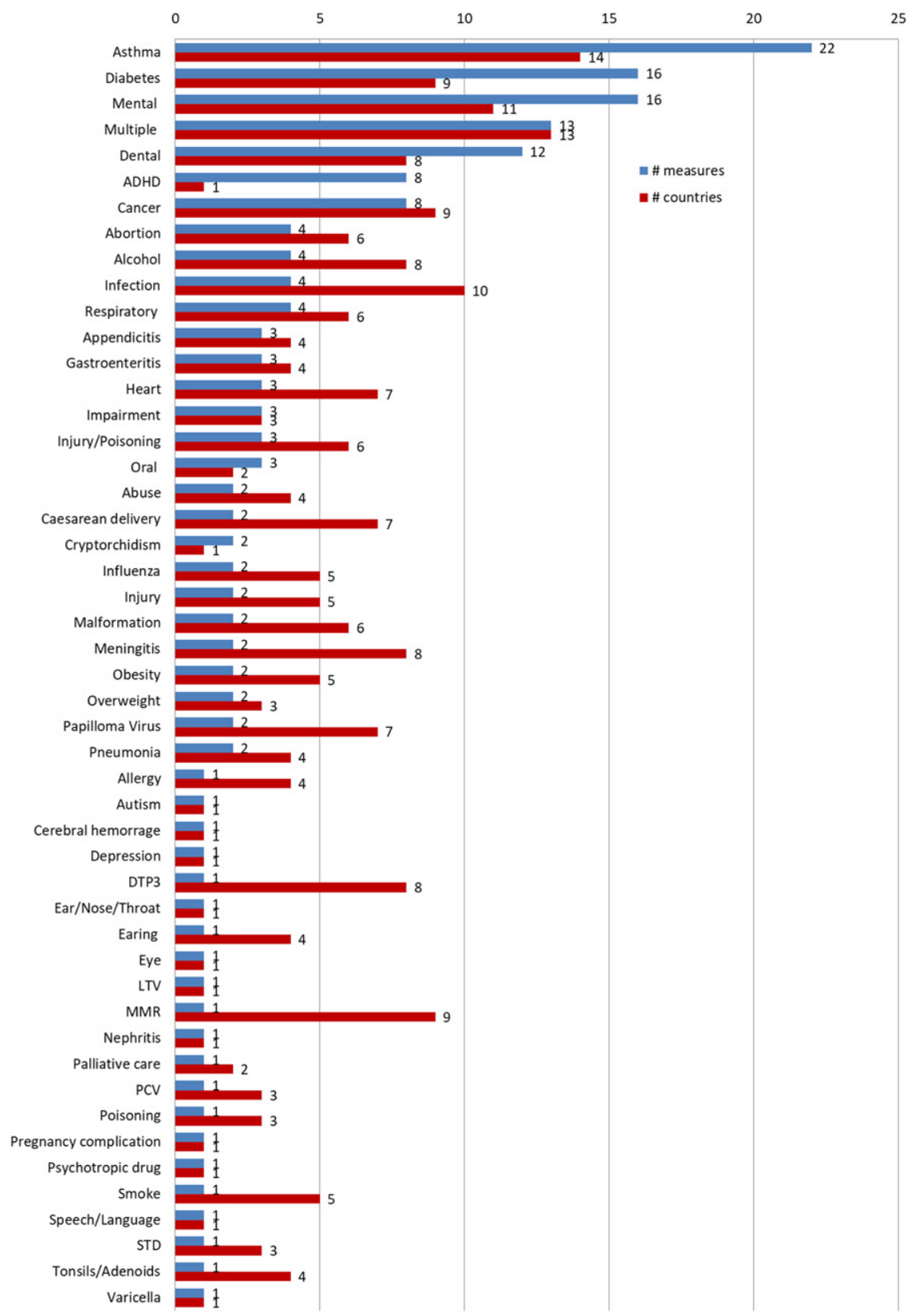

Figure 7.6. Distribution (n) of measures provided by CAs by disease. Total number of CAs reporting at least one measure related to the specific disease. 
measures that cover the whole period, making it difficult to track important stages of children's psychophysical development.

Age-related measures are generally focused on immunization, mortality and hospitalisation and this trend is confirmed also in the analysis of disease-related measures, leaving out other important aspects of childcare. At country level, as reported by CAs, there is a particular attention on asthma, diabetes and mental health, however analysed under different perspectives, making country comparison very difficult. The scattered presence on other disease-specific measures lets us presume that other morbidities may be included in the evaluation of care. There is little attention on the increasing number of children with noncommunicable diseases (Wolfe, 2013), or disability that pose crucial challenges for services provision (not only health-related) in a perspective of mitigating and enhancing quality of life of both children and their families.

Finally, and this is evident considering the whole range measures analysed (Minicuci et al., 2017), only a limited number of countries evaluate aspects connected with the provision of services, including health promotion and prevention activities or types and access to primary care child-centric services.

\section{Seeking Children's Data in Records-based Research Databases}

A third approach innovated by a team within the MOCHA project was to assess the potential of collaborative research using the considerable and much vaunted use of anonymised health databases drawn from record systems. This has been written up in the scientific literature (Liyanage, Hoang, Ferreira, \& de Lusignan, 2018). By utilising the local knowledge in each country of the CAs, and the specially designed MOCHA International Research Opportunity Instrument (MIROI) tool, a total of over 150 data repositories has been identified. Details of these, with metadata on custodianship, access and broad contents, were collated and stored securely on a health data cataloguing website. All the databases gave informed consent to these details being recorded, with the aspiration that comparative research could be undertaken on healthcare and health outcomes for the child patients recorded. Given the recognised importance of research on utilising real-world data from health care and actual patients, and the potential interest of all these databases, it was hoped that significant study could be undertaken of children's health care and outcomes for selected tracer conditions.

In the event, this vision did not materialise. As reported, there were significant problems of resourcing access (many database holders did not have time or financial resources to undertake even small one-off analyses, as these were not within the organised resource framework of the data-holding organisation). Secondly, there is no means of mutually recognising ethical approval or research validity across European countries (unlike within country, where there often is mutual recognition). Thirdly, data were not necessarily recorded in compatible ways or for the same aspects. 
So the MOCHA project hit another child data barrier. Even where potentially rich data were held and there was willingness to use these for service appraisal studies, the logistics meant that these data were in practice inaccessible, even though the foundational work of creating the downloaded database had already been undertaken. The child data repository was visible, but the data were inaccessible.

\section{Data: Financial Environment and Spending}

From an economics perspective, the starting point for analysing the focus on children in healthcare provision at a national level would be by exploring the data on healthcare expenditure. This would incorporate scrutiny of variables such as total healthcare expenditure per child, proportions that are publicly versus privately financed, the extent of out-of-pocket (OOP) expenditures by parents/carers and the distribution of expenditure (as a reflection of access to health care). Data on these variables, however, are not generally available. While some information is provided at the national level, and collated by international organisations such as the World Bank and the World Health Organization, it is not disaggregated to show the proportions of expenditure on children and young people, or how expenditure is distributed between primary and secondary care.

Total health expenditure per capita, public and private health spending per capita and OOP expenditure on health are shown in Table 7.6 for the MOCHA countries, providing some indication of how much each country spends in the area of health overall and how it is financed. Lags exist, however, in the compilation of these data such that those available may be some years out-of-date. Population size and the numbers of children and young people are also included, but little can be inferred from this about how much health care is absorbed by children without further detail on the age distribution of the whole population and relative expenditures across all age groups. It is likely that expenditure on older people is disproportionately high such that expenditure on children cannot be assumed to be a simple percentage of health expenditure equivalent to the proportion of children in the population. Hence, children are 'invisible' in national figures.

The major determinant of overall health expenditure in any country is its wealth, traditionally measured by its Gross Domestic Product (GDP) per capita. For the purposes of international comparisons, GDP is standardised to a common Purchasing Power Parity based on the US dollar. Significant variability in GDP per capita and health expenditures are apparent across the MOCHA countries with implications for the levels of healthcare provision, including for children. GDP per capita is an average figure and does not take account of the distribution of resources within countries which may be quite inequitable. National data are available on the proportions of children at risk of poverty but the relationship between income levels and access to health care cannot be established from the available data (Table 7.6). 
Table 7.6. National data on health expenditure and financing and for the MOCHA countries.

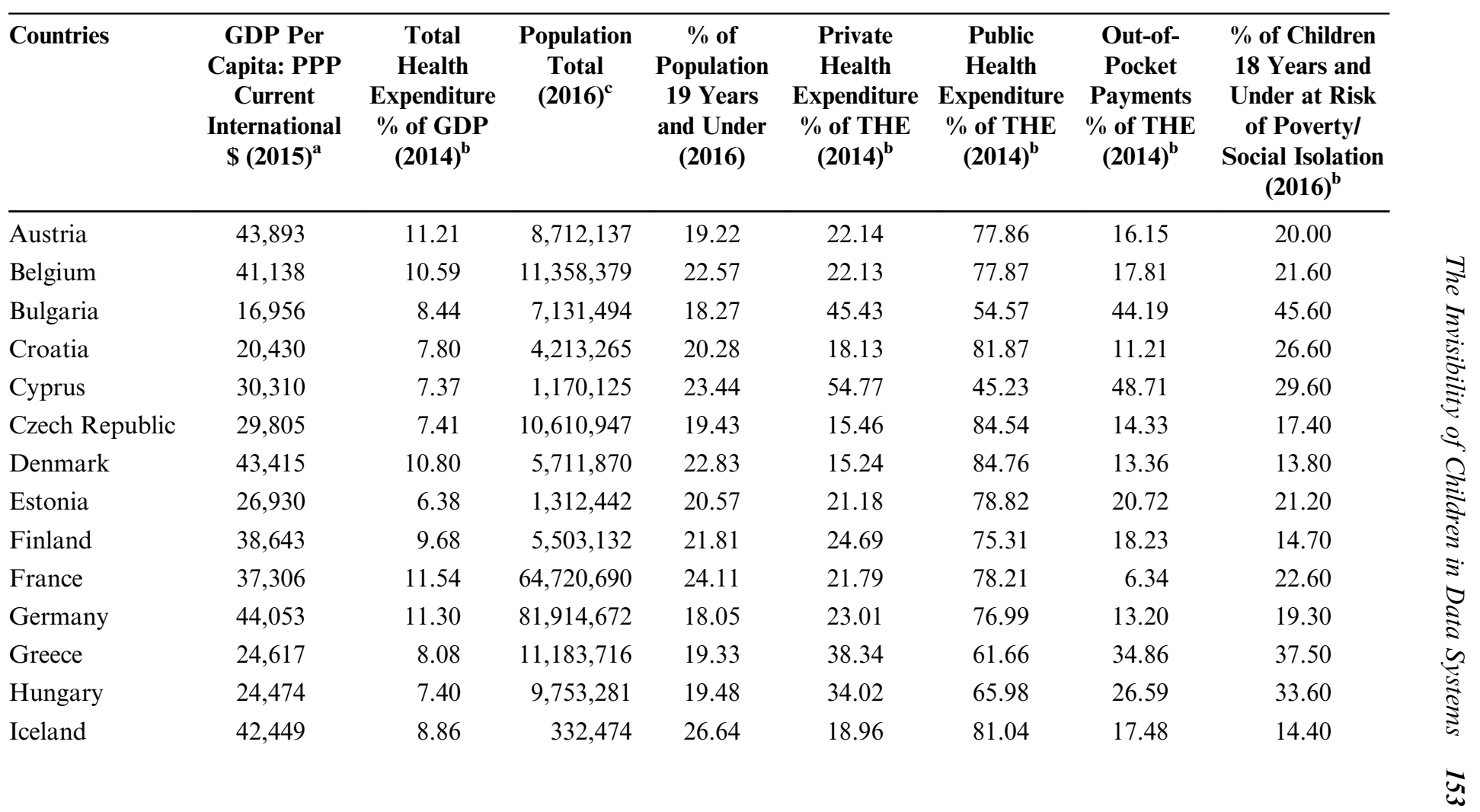


Table 7.6. (Continued)

\begin{tabular}{|c|c|c|c|c|c|c|c|c|}
\hline Countries & $\begin{array}{c}\text { GDP Per } \\
\text { Capita: PPP } \\
\text { Current } \\
\text { International } \\
\$(\mathbf{2 0 1 5})^{\mathbf{a}}\end{array}$ & $\begin{array}{c}\text { Total } \\
\text { Health } \\
\text { Expenditure } \\
\text { \% of GDP } \\
(2014)^{\mathbf{b}}\end{array}$ & $\begin{array}{c}\text { Population } \\
\text { Total } \\
(\mathbf{2 0 1 6})^{\mathbf{c}}\end{array}$ & $\begin{array}{c}\% \text { of } \\
\text { Population } \\
19 \text { Years } \\
\text { and Under } \\
(2016)\end{array}$ & $\begin{array}{c}\text { Private } \\
\text { Health } \\
\text { Expenditure } \\
\% \text { of THE } \\
(2014)^{b}\end{array}$ & $\begin{array}{c}\text { Public } \\
\text { Health } \\
\text { Expenditure } \\
\% \text { of THE } \\
(2014)^{\mathbf{b}}\end{array}$ & $\begin{array}{c}\text { Out-of- } \\
\text { Pocket } \\
\text { Payments } \\
\% \text { of THE } \\
(2014)^{b}\end{array}$ & $\begin{array}{c}\% \text { of Children } \\
18 \text { Years and } \\
\text { Under at Risk } \\
\text { of Poverty/ } \\
\text { Social Isolation } \\
(2016)^{\mathbf{b}}\end{array}$ \\
\hline Ireland & 51,899 & 7.78 & $4,726,078$ & 27.57 & 33.94 & 66.06 & 17.66 & 27.30 \\
\hline Italy & 33,587 & 9.25 & $59,429,938$ & 18.31 & 24.39 & 75.61 & 21.19 & 33.20 \\
\hline Latvia & 22,628 & 5.88 & $1,970,530$ & 19.46 & 36.82 & 63.18 & 35.13 & 24.70 \\
\hline Lithuania & 26,397 & 6.55 & $2,908,249$ & 20.19 & 32.13 & 67.87 & 31.27 & 32.40 \\
\hline Luxembourg & 93,553 & 6.94 & 575,747 & 22.40 & 16.07 & 83.93 & 10.60 & 22.70 \\
\hline Malta & . & 9.75 & 429,362 & 19.83 & 30.84 & 69.16 & 28.86 & 24.00 \\
\hline Netherlands & 46,374 & 10.90 & $16,987,330$ & 22.53 & 13.00 & 87.00 & 5.22 & 17.60 \\
\hline Norway & 64,451 & 9.72 & $5,254,694$ & 24.06 & 14.51 & 85.49 & 13.61 & 14.90 \\
\hline Poland & 24,836 & 6.35 & $38,224,410$ & 19.90 & 29.02 & 70.98 & 23.46 & 24.20 \\
\hline Portugal & 26,690 & 9.50 & $10,371,627$ & 19.13 & 35.18 & 64.82 & 26.84 & 27.00 \\
\hline Romania & 19,926 & 5.57 & $19,778,083$ & 20.75 & 19.60 & 80.40 & 18.87 & 49.20 \\
\hline Slovakia & 27,394 & 8.05 & $5,444,218$ & 20.44 & 27.49 & 72.51 & 22.54 & 24.40 \\
\hline Slovenia & 28,942 & 9.23 & $2,077,862$ & 19.33 & 28.27 & 71.73 & 12.07 & 14.90 \\
\hline Spain & 32,814 & 9.03 & $46,347,576$ & 19.34 & 29.12 & 70.88 & 23.99 & 32.90 \\
\hline
\end{tabular}




$\begin{array}{lrrrrrrrr}\text { Sweden } & 45,296 & 11.93 & 9,837,533 & 22.46 & 15.97 & 84.03 & 14.06 & 19.90 \\ \text { United } & 38,658 & 9.12 & 65,788,574 & 23.30 & 16.86 & 83.14 & 9.73 & 27.20 \\ \text { Kingdom } & & & & & & & & \end{array}$

Sources: ${ }^{\text {aW }}$ World Bank, International Comparison Program database.

${ }^{b}$ World Health Organization Global Health Expenditure database.

${ }^{c}$ United Nations, Department of Economic and Social Affairs, Population Division (2017). World Population Prospects.

Notes: GDP - gross domestic product; PPP - purchasing power parity; THE - total health expenditure.

Definition of Health Expenditure and Financing Variables.

Total health expenditure is the sum of public and private health expenditure. It covers the provision of health services (preventive and curative), family planning activities, nutrition activities and emergency aid designated for health but does not include provision of water and sanitation.

OOP expenditure is any direct outlay by households, including gratuities and in-kind payments, to health practitioners and suppliers of pharmaceuticals, therapeutic appliances and other goods and services whose primary intent is to contribute to the restoration or enhancement of the health status of individuals or population groups. It is a part of private health expenditure.

Private health expenditure is the share of current health expenditures funded from domestic private sources. Domestic private sources include funds from households, corporations and non-profit organisations. Such expenditures can be either prepaid to voluntary health insurance or paid directly to healthcare providers.

Public health expenditure is the share of current health expenditures funded from domestic public sources for health. Domestic public sources include domestic revenue as internal transfers and grants, transfers, subsidies to voluntary health insurance beneficiaries, non-profit institutions serving households (NPISH) or enterprise financing schemes as well as compulsory prepayment and social health insurance contributions. They do not include external resources spent by governments on health.

Like GDP per capita, health expenditure figures are average spends per individual in the population and allocation to primary vs secondary care, or by age or income group are difficult to isolate. 


\section{Conclusion}

There are many aspects to the collation of necessary data about children's health, the provision of services to children and understanding of the environmental and services context. But a strong theme to emerge in this chapter is the invisibility of children. Despite the universal use of the United Nations Convention on the Rights of the Child, children as correctly therein defined are invisible in almost all data systems. The four quinquennial age bands are common, as is also sometimes analysis for the first year of life. But children as a legally defined group, and as a group with clear service needs, do not feature in Europe's or the world's data systems. A further complication is added by those system policies, or legislative rules, that make 16 years a watershed age, as this too is universally ignored statistically.

The outcome of this is that children overall cannot be represented in statistical or policy analyses in a way matching that of other population groups. Secondly, it means that the analyses and policies that are produced are subject to an imprecision, and to potential argument about their data and framing, because the statistical margins are not fixed. A particular consequence is that adolescents, themselves at a rapidly changing and sometimes personally challenging stage of their life course, are the most invisible age group. To say that this is unsatisfactory would be a gross understatement.

Finally, though, this chapter unfortunately is a definition of how nearly all systems in European society and policy pay lip service to the importance of children, but do not really accommodate them. Nearly all data sources in Europe are now digitised at the point of data capture, so the subsequent aggregation and analysis is software driven, and rightly. But this also means that the effort of adjusting software to produce a split of the 15-19 years age group and producing a further analysis for children, would be minimal. It is regularly and easily done when analysing by country, with aggregates for instance for the early EU 15, the current EU 28, the future EU 27 or the whole of geographical Europe. But similar effort for the children who live in Europe does not happen.

Similarly, other good intents or policy visions are not followed through in children's interests. This ranges from the low policy response to the recommended monitoring datasets for children from the CHILD project, (Rigby \& Köhler, 2002) commissioned by an initiative which envisaged development of an information system which would have a children's dashboard view, but 16 years later is in effect ignored, through to lack of creation of a simple policy and ethical framework which would enable collaborative analysis of the rich anonymised databases which hold real-world people-based data. Overall, this is a disappointing statement and demonstration of children's low value in policy terms in Europe.

\section{References}

Central Intelligence Agency. (2018). The world factbook. Retrieved from https:// www.cia.gov/library/publications/resources/the-world-factbook/

Chapple, S., \& Richardson, D. (2009). Doing better for children. Paris: OECD Publishing. 
Eurostat. (2018a). European statistics, overview. Retrieved from https://ec.europa.eu/ eurostat/about/overview

Eurostat. (2018b). European statistics, database. Retrieved from https://ec.europa.eu/ eurostat/data/database

Global Burden of Disease. (2016). Pediatrics collaboration, global and national burden of diseases and injuries among children and adolescents between 1990 and 2013: Findings from the global burden of disease 2013 study. The Journal of the American Medical Association- Pediatrics, 170(3), 267-287.

HBSC Data Portal. (2018). Retrieved from http://hbsc-nesstar.nsd.no/webview/

Health Behaviour in School-aged Children. (2018). About HBSC. Retrieved from http://www.hbsc.org/about/index.html

Institute for Health Metrics and Evaluations (IHME). (2018a). About IHME. Retrieved from http://www.healthdata.org/about

Institute for Health Metrics and Evaluations (IHME). (2018b). Global health data exchange (GHDx), GBD results tool. Retrieved from http://ghdx.healthdata.org/ gbd-results-tool

Leach-Kemon, K., \& Gall, J. (2018). Why estimate? Retrieved from http://www. healthdata.org/acting-data/why-estimate?utm_source=IHME+Updates\&utm_campaign=c062742ac8-Weekly_Email_Sep_6_2018\&utm_medium=email\&utm_term= 0_1790fa6746-c062742ac8-422568873

Liyanage, H., Hoang, U., Ferreira, F., \& de Lusignan, S. (2018). Report of measures of quality and outcomes derived from large datasets. Retrieved from http://www. childhealthservicemodels.eu/wp-content/uploads/Deliverable-D14-5.2-Report-ofMeasures-of-Quality-and-Outcomes-derived-from-large-data-sets.pdf

Minicuci, N., Corso, B., Rocco, I., Luzi, D., Pecoraro, F., \& Tamburis, O. (2017). Innovative measures of outcome and quality of care in child primary care models. Retrieved from http://www.childhealthservicemodels.eu/wp-content/uploads/2015/ 09/D7-Identification-and-Application-of-Innovative-Measures-of-Quality-and-Outcome-of-Models.pdf

OECD. (2009). Doing better for children. Paris: OECD. Retrieved from www.oecd. org/els/social/childwellbeing

Organisation for Economic Cooperation and Development (OECD). (2013). OECD. Stat Web browser user guide. Retrieved from https://stats.oecd.org/Content/ themes/OECD/static/help/WBOS\%20User\%20Guide\%20(EN).PDF

Organisation for Economic Cooperation and Development (OECD). (2018a). About us. Retrieved from www.oecd.org/about/

Organisation for Economic Cooperation and Development (OECD). (2018b). Health. Retrieved from www.oecd.org/health/

Organisation for Economic Cooperation and Development. (2018c). OECD.Stat Web browser. Retrieved from https://stats.oecd.org/index.aspx?DataSetCode= HEALTH_STAT

Rees, G., Bradshaw, J., Goswami, H., \& Keung, A. (2006). Understanding children's well-being: A national survey of young people's well-being. The Children's Society. Retrieved from https://www.childrenssociety.org.uk/sites/default/files/tcs/ research_docs/Understanding $\% 20$ children $\% 27 \mathrm{~s} \% 20$ wellbeing.pdf

Rigby, M., \& Köhler, L. (2002). Child health indicators of life and development (CHILD): Report to the European Commission. European Commission Health 
Monitoring Programme. Retrieved from https://ec.europa.eu/health/ph_projects/ 2000/monitoring/fp_monitoring_2000_frep_08_en.pdf

Rigby, M. J., Köhler L. I., Blair, M. E., \& Mechtler, R. (2003). Child health indicators for Europe - A priority for a caring society. European Journal of Public Health, 13(3 Supplement), 38-46.

Roberts, C., Freeman, J., Samdal, O., Schnohr, C. W., de Looze, M. E., Nic Gabhainn, S., ... International HBSC Study Group et al. (2009). The health behaviour in school-aged children (HBSC) study: Methodological developments and current tensions. International Journal of Public Health, 54, S140-S150. doi:10.1007/s00038-009-5405-9

The World Bank. (2018a). About us. Retrieved from https://data.worldbank.org/about

The World Bank. (2018b). Open data, indicators. Retrieved from https://data.worldbank.org/indicator

The World Bank. (2018c). DataBank, health nutrition and population statistics database. Retrieved from http://databank.worldbank.org/data/source/health-nutritionand-population-statistics

UNICEF. (2009). The state of the world's children: Maternal and newborn health. Retrieved from https://www.unicef.org/sowc09/

United Nations Population Division. (2017). European population counter. Retrieved from http://www.worldometers.info/world-population/europe-population/

Wolfe, I. (Ed.). (2014). European child health services and systems: Lessons without borders. Retrieved from http://www.euro.who.int/_data/assets/pdf_file/0003/ 254928/European-Child-Health-Services-and-Systems-Lessons-without-borders.pdf

World Health Organization Regional Office for Europe. (2014). Investing in children: The European child and adolescent health strategy 2015-2020. Copenhagen. Retrieved from http://www.euro.who.int/_data/assets/pdf_file/0010/253729/64wd12e_ InvestCAHstrategy_140440.pdf?ua=1)

World Health Organization Regional Office for Europe. (2016). Improving the quality of care for reproductive, maternal, neonatal, child and adolescent health in the WHO European Region: A regional framework to support the implementation of Health 2020. Copenhagen. Retrieved from http://www.euro.who.int/_data/assets/ pdf_file/0009/330957/RMNCAH-QI-Framework.pdf?ua=1

World Health Organization, Regional Office for Europe. (2017). Child and adolescent health, data and statistic. Retrieved from http://www.euro.who.int/en/healthtopics/Life-stages/child-and-adolescent-health/data-and-statistics

World Health Organization, Regional Office for Europe. (2018a). European health information gateway, health for all explorer. Retrieved from https://gateway.euro. who.int/en/hfa-explorer/

World Health Organization, Regional Office for Europe. (2018b). Child and adolescent health dataset. Retrieved from https://gateway.euro.who.int/en/datasets/cah/. Accessed on October 15, 2018.

World Health Organization, Regional Office for Europe. (2018c). Child and adolescent health, health behaviour in school-aged children (HBSC). Retrieved from http://www.euro.who.int/en/health-

World Health Organization. (2010). Monitoring the building blocks of health systems: $A$ handbook of indicators and their measurement strategies. Retrieved from http:// www.who.int/healthinfo/systems/WHO_MBHSS_2010_full_web.pdf 